\title{
A New Lens for Seeing: A Suggestion for Analyzing Religious Belief and Belonging among Emerging Adults through a Constructive-Developmental Lens
}

\author{
Theresa A. O'Keefe *(1) and Emily Jendzejec * \\ School of Theology \& Ministry, Boston College, Chestnut Hill, MA 02467, USA \\ * Correspondence: theresa.okeefe@bc.edu (T.A.O.); Emily.jendzejec@bc.edu (E.J.)
}

Received: 3 October 2020; Accepted: 28 October 2020; Published: 2 November 2020

\begin{abstract}
In recent years, there has been an explosion of research on the religious lives of adolescents and emerging adults. Methodologies vary from large-scale quantitative surveys to smaller qualitative interview protocols. Findings point to a significant drop in religious affiliation among emerging adults. Making good sense of the findings can be difficult for ministers and educators who serve across these populations. In this article, we suggest using a constructive-developmental lens to read qualitative findings. We offer a framework to guide researchers in interpreting the narratives of research subjects, noting how they make sense of religious belief and belonging.
\end{abstract}

Keywords: disaffiliation; religious belief; religious belonging; emerging adults; young adults; constructive-developmental; qualitative research

\section{Introduction}

According to Pew Research, one fifth of the US public and a third of adults under thirty are religiously unaffiliated. The 2012 Pew Research study "“Nones” on the Rise: One-in-Five Adults Have No Religious Affiliation" was designed "to delve more deeply into the theological, social and political views of the large and growing number of Americans who have no religious affiliation" (Funk and Smith 2012, p. 7). The Pew Research publication gained national attention in popular news publications, but the data was not a shock to religious leaders, educators, and sociologists of religion. Several other studies around that time and since have been conducted and published concerning the same phenomenon of disaffiliation from religious traditions in the United States: (Chan et al. 2015; Streib et al. 2009; Funk and Smith 2012; Beaudoin and Hornbeck 2013; Packard and Hope 2015; Smith and Snell 2009; Thurston and ter Kuile 2012; Kosmin and Keysar 2013; Dalessandro 2016). Most relevant to our interests are several studies that look specifically at Catholic emerging adults (Overstreet 2010; Byron and Zech 2012; Smith et al. 2013; McCarty and Vitek 2018).

While all studies concur that there is a growing trend of disaffiliation among emerging adults, diverse methods by researchers have been used to get at this reality, including large-scale quantitative (Chan et al. 2015; Kosmin and Keysar 2013), small-scale qualitative (Overstreet 2010; Byron and Zech 2012; Dalessandro 2016), and mixed-method studies (Smith and Denton 2005; Smith and Snell 2009; Smith et al. 2013; McCarty and Vitek 2018). The religiously disaffiliated are those who were raised within the church (i.e., baptized) but who are no longer connected with the institutional church nor actively engaged in church communities. Some studies do not inquire into the nature of disaffiliation (Funk and Smith 2012), whereas others speak of disaffiliation as a "largely a thoughtful, conscious, intentional choice" (McCarty and Vitek 2018, p. 11). Still others refer to the experience as "deconversion", a decided identification away from a religious community towards a thoughtful path of one's own making (Beaudoin 2013; Streib et al. 2009). 
In order for religious communities to respond effectively and appropriately to disaffiliation, it is important to grasp as accurately as possible what is driving the trend. To make the best use of the data, we suggest that it is important for researchers to interpret their material through helpful lenses. In this paper, we propose a lens based on the constructive-developmental theory of Kegan (1994). This lens offers an epistemological framework for recognizing the cognitive development of meaning-making. It might be used to code interviews from existing qualitative projects or provide a conceptual foundation for future projects so as to provide a richer interpretation of the data. This would provide religious leadership greater direction in responding to the formative and religious needs of emerging adults, those between 18 and 30 years of age (Arnett 2004). The essay has three sections. The first very briefly names a few examples of the three dominant modes of current research from the United States with regard to disaffiliation among emerging adults and names a limitation to each. The second section introduces constructive-developmental theory as a lens through which to read qualitative interviews. The third section offers two examples of interpreting and analyzing interviews using a constructive-developmental lens.

\section{Research Trends on Religious Belief and Belonging among Emerging Adults}

In this section, we highlight a few examples of current research methods: large-scale quantitative, mixed method, and qualitative. We identify a value and limit to these modalities, setting up our argument for the value of interpreting research through a constructive-developmental lens.

Large-scale quantitative research can be very valuable for noting major trends and the correlation among factors. The 2012 Pew Research study is a notable large-scale quantitative study, backed by decades of practice in the field. While valuable for noting trends, such studies can be of limited value to religious ministers and educator because they do not determine causation nor provide a specific lens through which to interpret the findings. Additionally, perhaps the greatest challenge in designing large-scale studies is writing the questionnaire or survey apparatus. Creating questions that get at the complexity of the constructs under investigation while being appropriately meaningful to a wide variety of respondents is a time-consuming process, and should involve testing and reworking in the design process. Another example of a large-scale study is the American Religious Identification Survey ARIS National College Student Survey series, which has deepened the understanding of religious identification among college students over the past two decades and has validated "Secular" as a distinct worldview (Kosmin and Keysar 2013). Yet, the 2013 ARIS is an example of poor question design. While some of the questions offer a Likert response scale, many of the questions reflect binary choices. Furthermore, they frequently use language about religious belief that can be found in the public square, but not necessarily within religious communities. As one example among several, they offer a yes or no response to the following questions: "Do you believe in Creationism/Intelligent Design? Do you believe in Evolution/Darwinism?" (Kosmin and Keysar 2013, p. 21). These questions do not reflect the nuance that might be discovered as differences within and among religious communities around life's origins and may be very difficult for many religious believers to answer appropriately. While large-scale quantitative studies have deepened our understanding of religious identification in the past two decades, providing large samples, it is difficult to design survey questions that reflect the great nuance of religious belief and belonging.

Mixed-methods research has the benefit of identifying themes through large-scale surveys that are augmented by interviews that illustrate the survey findings. For example, in 2015 St. Mary's Press commissioned the Center for Applied Research in the Apostolate (CARA) to conduct a survey of adolescents and emerging adults (ages 15-25) in the hope of understanding "more fully why young people leave the Catholic Church in particular" (McCarty and Vitek 2018, p. 5). CARA conducted a telephone survey with 204 respondents who identified as having disaffiliated from the Catholic Church. Fifteen subjects were later interviewed more fully on their history and reasons for disaffiliation. The survey data was analyzed for themes and demographics. They identified six "common dynamics for disaffiliation", and they found that, for those interviewed, disaffiliation had been a largely thoughtful 
and conscious choice (McCarty and Vitek 2018, p. 11). The researchers identified three categories into which adolescents and emerging adults interviewed could be placed: the injured, the drifters, and the dissenters (McCarty and Vitek 2018, p. 3). While the study did well to identify categories of disaffiliation, there was no further lens through which the analysis was conducted. For example, the interpretation of the interviews might have accounted for the developmental process that youth are going through. Instead, the youth's words are taken at face value without taking into account either the individual's context or their cognitive, social, or emotional development. Another major mixed-methods effort, the National Study of Youth and Religion (Smith and Denton 2005; Smith and Snell 2009; Smith et al. 2013), also received this critique (Bergler 2005).

Finally, qualitative research is usually small scale and depends on coding interviews for themes, often using an interpretive lens. Overstreet conducted in-depth, semi-structured interviews with twenty students at a single Catholic university. The purpose of this study was to examine how undergraduate Catholics attending a Catholic university "conceive of themselves as spiritual or religious and the differences, if any, between the two descriptors" (Overstreet 2010, p. 238). Overstreet used an interpretive phenomenological lens of psychosocial development to analyze students' responses, taking into account their development as college students. For example, she writes:

The students' reflections on their religious and spiritual beliefs and practices often conveyed a longing for independence and autonomy (e.g., not going to church because your parents tell you [Molly], disagreeing with your parents so they know you have developed your own beliefs [Justin]). (Overstreet 2010, p. 259)

The example reveals that Overstreet's analysis goes beyond taking the student's words at face value. Instead, she takes into account the interior processing of the individual and their cognitive development as college students.

Of the studies briefly reviewed above, Overstreet's is the only one that identifies an explicit lens through which she analyzed the interviews and does not claim to take the words at face value. Overstreet is also the only one to acknowledge that, as a researcher, she is also an interpreter; she writes, "when analyzing data there is an inevitable 'interpretation' of meanings made by both the subject and the researcher" (Overstreet 2010, p. 250). In this, she acknowledges that the researcher is always also an interpreter. We appreciate Overstreet's approach of interpreting data on religious belief and belonging through the lens of cognitive development. However, we encourage a deeper analysis using a constructive-developmental lens in order to better understand what is going on internally for emerging young adults who choose to disaffiliate from religion.

\section{Recognizing the Cognitive Development of Emerging Adults}

How best to study religious belief and belonging among emerging adults? In one respect, religious communities could be studied like other membership organizations (e.g., team sports, civic organizations, buying clubs), tracking the rise and fall of membership or affiliation. Since religious communities profess beliefs, it could make sense to inquire about an individual member's agreement with those beliefs or not. However, religious belonging and belief are more complex than what is measurable in a binary fashion ("Do you believe or not?") or a Likert scale ("To what degree do you affiliate or not?"). Discrete religious beliefs together construct a worldview of life's ultimate source, meaning, purpose, and hope. That ultimate worldview is reflected in myriad day-to-day practices, moral injunctions, forms of worship, and the ways in which a religious community gathers and perpetuates. While all connected, one aspect does not reveal the whole worldview. Thus, agreement or disagreement with a discrete aspect may not tell us anything about an individual's larger worldview or how religious belief influences that worldview. Furthermore, religious beliefs and practices may continue to have an impact on an individual's meaning-making even when explicit membership or affiliation has ended. 
Inquiring about belief and belonging may be best suited for a qualitative project, with open-ended questions in a semi-structured interview. However, beyond a better inquiry process, we believe a better lens is needed to interpret what is heard. We believe that a constructive-developmental lens may be a very valuable lens for coding qualitative research conducted along this line of inquiry. Interpreting through a constructive-developmental lens can help us recognize how religious belief and belonging impacts a young person's meaning-making, their worldview and self-understanding, and their commitments in life. The effectiveness of this lens lies in the researcher's ability to interpret how the interviewee speaks about religious beliefs, practices, values, and affiliation, and not whether the interviewee makes explicit claims for or against religion.

\subsection{Seeing through the Cognitive-Developmental Lens}

To understand the value of this lens for interpretation, it is essential to understand something about how it functions to understand a person's cognitive capacity for meaning-making. Because our interest is in emerging adults, we focus on the shift in meaning-making a young person is likely to make when moving from childhood, through adolescence, and to adulthood, looking to the work of Robert Kegan. Kegan's work comes out of the cognitive developmental school pioneered by Jean Piaget (Kegan 1982, 1994). In developing his theory, Kegan uses a qualitative methodology, using an interview process that pays attention to how people express themselves rather than what they profess (Lahey et al. 2011). In focusing on the how, Kegan looks to discover the interview subject's cognitive capacity for meaning-making.

Kegan conceives of each developmental "stage" as reorienting; what was understood previously is not forgotten, but reorganized or re-centered in light of what is newly perceived. Kegan describes this "principle of mental organization" as the "the subject-object relationship" (Kegan 1994, p. 32). In the process of assessing the meaning-making capacity of the interviewee, Kegan notices what the interview subject holds as object (e.g., what they believe they can manipulate or determine) and to what they are subject (e.g., the unnamed or given and beyond their control). According to constructive-developmental theory, development occurs through the knower disembedding from that to which they were subject, such that it becomes object, thus making it possible (and necessary) to make new sense of their world and of themselves. Kegan explains further, "One does not simply replace the other, nor is the relation merely additive or cumulative, an accretion of skills. Rather, the relation is transformative, qualitative, and incorporative. Each successive principle subsumes or encompasses the prior principle" (Kegan 1994, p. 33). What is subject becomes the organizing principle of what is object. Kegan makes a geometric analogy: a point is subsumed in a line, which is further subsumed in a plane. Each more complex frame organizes, but does not negate, the earlier element; rather, the earlier is included and organized within a larger frame of reference.

According to Kegan, what he identifies as second-order consciousness comes into play as the older child is able to recognize the difference between concrete reality and fantasy. Within second-order consciousness, the world becomes one of "durable categories"; that which is concrete and immediate is observable and able to be manipulated-it is object. This cognitive capacity requires what Piaget named as concrete-operational thought. However, what the second-order knower cannot see-what they are still subject to-are the intent or value behind the concrete. They cannot see the themes or abstractions which may unite, connect, or order the concrete-those are subject.

The ability to recognize intent, design, or overarching theme is the ability of Kegan's third-order consciousness. The third order requires the capacity Piaget called formal-operational thought-the cognitive capacity to ideate or think thematically. With the shift to third order, one gains the capacity to recognize that groups of people (family, church, team, and friends) are not simply a gathering of individual actors, but a collective with a shared meaning and purpose (to be family, or church, or teammate, or friend). Furthermore, the third-order knower now can subordinate their personal desires and point of view to "loyalty and devotion to a community of people or ideas larger than the self" (Kegan 1994, p. 32). In light of Kegan's theory, we suggest that it requires at least third-order capacity 
to knowingly affiliate or disaffiliate based on a conception of belonging that is beyond pure circumstance or self-interest. In the third order, one develops the capacity for agency over one's affiliation as such. Prior to third order, choices to go along or not are based on the more limited perspective of self-interest or circumstance and less on the more complex awareness of and choice for or against association.

Kegan's constructive-developmental framework tracks growth well into adulthood, with each order expanding beyond the cognitive complexity of the prior order. Whereas the second-order knower can categorize concrete, observable, and immediate objects but cannot think in ideas or themes, and the third-order knower reflects the capacity for ideation (to organize and think thematically about concrete realities), beyond that, the fourth-order knower reflects the ability to think ideologically (to organize and prioritize among ideas and themes). According to Kegan, this fourth-order capacity of mind, known as "systemic-complex" (Kegan 1994), is most likely to develop, if it develops at all, in later adulthood. As such, it is largely beyond the consideration of this brief article.

\subsection{Translating the Constructive-Developmental Lens to Religious Setting}

How might we recognize constructive development in terms of religious belief and belonging so as to use it as an interpretive lens? Similar to Kegan's analogy of point-line-plane and following the kind of development that can happen through adolescence to adulthood (from concrete-operational to formal-operations, then complex ideation), we suggest the schema of practice-value ideology. This schema reflects the kind of elements found within religious traditions (practices, values, and ideologies) and organizes them from the concrete, to thematic, to complex/systemic. Each becomes the organizing principle for the previous, and an ultimate claim about life's source and purpose becomes the highest organizing principle. This is not to pre-determine what that ultimate claim is, but that the ultimate claim is the highest organizing principle.

For example, practices may include the concrete realities of worship and prayer, community membership, and activities, such as reading from scripture, but also moral injunctions and prohibitions for behavior as well as concrete actions, words, and thoughts. Values would include commitments to beliefs that inform and determine the practices and moral injunctions, but also the commitments to the community that holds those beliefs. In aggregate, values can compose a moral framework or what it means to be a member of a particular community. Finally, values are assigned their value-and moral frameworks their framing - by a grounding ideology. Ideologies include the theological perspectives that shape and prioritize the values and the community. Ideologies point toward ultimate ends, such as life's meaning, direction, or purpose, even if those ultimate ends are unnamed. Finally, belief about what is ultimate organizes and prioritizes the ideologies. Imagined as concentric circles (Figure 1), each circle is the organizing principle for the circle interior to it. Our values shape what practices we think are important; likewise, our ideology shapes which values are prioritized over others, and all are shaped by what is believed to be ultimate in life. This is not to suggest that religious worldviews are always so neatly held in this nested way. It is to argue that the capacity of an individual to knowingly speak about practices, values, or ideologies gives the researcher insight into the cognitive capacity of the interview subject and how religious belief and belonging factor in the construction of their worldview. 


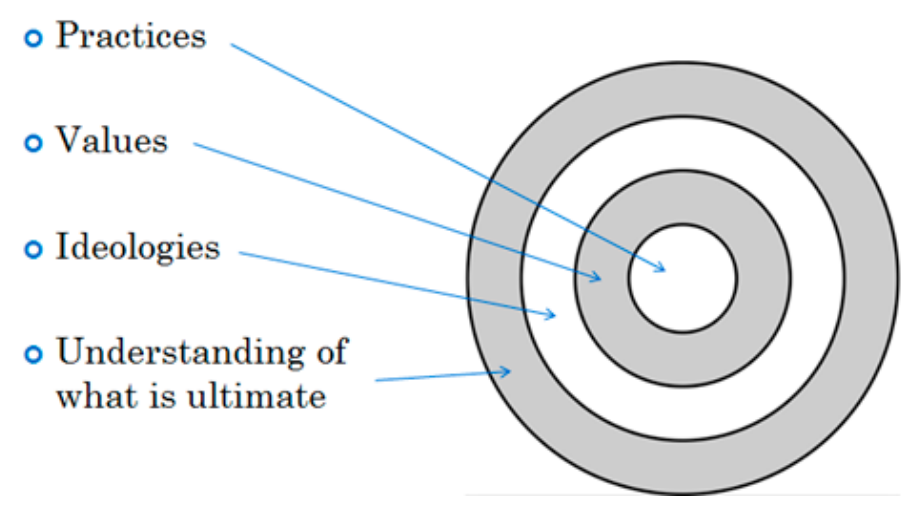

Figure 1. Schema reflecting the relationships among different classes of knowledge.

What of the person who makes no ultimate claim? Philosopher Charles Taylor makes a compelling argument that, regardless of whether an ultimate claim is expressed or not, it can be inferred by what priorities and values are chosen, which practices are encouraged or sanctioned. Each "lesser" choice suggests some greater sense of "the good life" (Taylor 1989). This argument helps us recognize how choices for immediate and concrete practices can suggest some larger framework of meaning, values, ideologies, or claims of ultimate good.

Imagined in this way, the constructive-developmental framework can be a helpful lens through which we interpret research on religious belief and belonging among adolescents and emerging adults because it gives us a means of paying attention to what research subjects say about religious belief and belonging. Is the interview subject able to ideate and discuss issues from a thematic level, or are they limited to talking about concrete practices? For example, do they speak of the moral injunctions of their religious community as arbitrary, indicating only how they impact them personally, without demonstrating any ability to name the values intended in those injunctions? In this instance, we would say that practices are object, but the values remain subject. Such is not a value judgement about the person's life of faith, but it gives us a sense of their cognitive capacity for making meaning of religious belief and belonging. It can also tell us where their agency lies. For the person functioning at second order, relative to religious belief, their agency is in their ability to choose to do something or not; it is not in their ability to knowingly align (or not) with a moral framework as such. In such a case, the minister or educator may want to spend more time speaking compellingly about the values the church upholds in those practices.

On the other hand, if the person is able to speak about the values of the religious community and their intersection with (or divergence from) their own values, we might identify them as having third-order capacity, wherein their agency would be in their capacity to knowingly align (or not) with the values held by the community. Again, this is where interpretation can get interesting and valuable for the minister or educator. For example, the third-order knower may agree with the values of the religious community, but find the moral or religious injunctions out of line with those professed values, and so choose not to follow or support the injunctions. In this case, they are engaging with the tradition knowingly, but seeing contradictions within its practice. This might be a sign of misunderstanding or prophecy. This level of disagreement is much different from the second-order knower, who would choose not to follow simply because they do not want to, not because they understand and disagree.

Along with more accurately interpreting the meaning of an individual's religious belief and belonging, such a lens can be a helpful guide for religious ministers and educators to develop initiatives and interventions that are appropriate to the way emerging young adults are coming to see and make sense of religion. However, that discussion is beyond the scope of this paper. 


\section{Reading through the Constructive-Developmental Lens}

In this section, we demonstrate how the use of a constructive-developmental lens can make better sense of the first person narratives on religious belief and belonging, by offering a few examples drawn from interviews found in existing studies. These examples are only brief illustrations of how to read accounts through the constructive-developmental lens. They are not a full analysis of the interview subjects. Such analysis would require the complete transcripts and any research notes surrounding those transcripts. Our examples use the statements of two subjects-Diane and Edward-drawn from Going, Going, Gone (McCarty and Vitek 2018).

\subsection{Seeing beyond the Concrete, But...}

It is noteworthy that Diane names an extensive list of religious practices in which she was involved as a child and adolescent (receiving sacraments, serving at liturgy as an altar server and a Eucharistic minister, attending annual school retreats, and completing service hours) (McCarty and Vitek 2018, pp. 27-28). For all intents and purposes, she is someone religious leaders might hope and expect to be deeply rooted in belief and belonging. However, she no longer carries on those practices. Why? What meaning do they have for her?

Using the constructive-developmental lens, we note Diane's growth beyond basic concrete-operational thought towards formal operations because some of her statements demonstrate her ability to ideate and think in terms of values; she repeatedly named the value of choice. In the following statements, she bemoans her lack of choice in childhood and lauds her right to choose that comes later:

But in reality, kids go to church because they think that is what kids do, they don't realize they have a choice. (McCarty and Vitek 2018, p. 22)

It was not until I went to college that I was officially out of the Catholic Church. I was no longer forced to be Catholic. When this finally happened I was relieved and happy, really now I was able to make my own decisions. I have never went back to church. (McCarty and Vitek 2018, p. 27)

I went to Catholic schools from kindergarten through high school. That was something that I did not have a choice in either. (McCarty and Vitek 2018, p. 27)

In each of these, we notice that she not only names choice, but can apply it to multiple situations, reflecting a capacity to work with choice as a value. Yet, we should also notice that her lack of freedom did not come from religious injunctions, but from parental restrictions. While still limited in some ways to the self-referential concern of the second-order knower, her statements indicate that she is gaining the capacity for formal operational thought, a necessary precursor for third-order knowing.

However, never once does she speak of the many religious practices she followed in terms of any value they represented. Similarly, she identifies a few moral injunctions and prohibitions, but only speaks of them as a restriction to freedom, with no articulation of the values intended in the prohibitions: "I believe in birth control...I am a complete supporter of gay marriage and being able to choose who you want to be with. I am fine with priests being able to get married" (McCarty and Vitek 2018, p. 21). She shows some capacity to ideate in her discussion of freedom of choice. Yet, when it comes to religious belief and belonging, she demonstrates the immediate, concrete, and self-referential thinking of second-order knowing, and never refers to any values they represent, suggesting that they remain invisible to her.

As discussed above, the second-order knower is able to follow instructions and prohibitions (e.g., teachings on birth control), but is not able to communicate or understand the motives or values behind those instructions or prohibitions. The practice is object, but the intention or value remains subject. Initial growth beyond second order may be identified in Diane's ability to speak in terms 
of ideas, themes, and values, even if the source of such values (e.g., family, religion, society at large) are not consciously attributed. Without being particularly instructed, Diane may infer meaning and values from the social surrounding (Bronfenbrenner 1979, 2005). In this case, Diane is able to speak extensively of the value of freedom choice, as it is widely and diversely communicated in the culture at large as the ability to do what one wants. On the other hand, she does not speak of the values inherent in the many religious practices, nor does she speak of freedom as understood within a Christian framework, such as the freedom to choose right and wrong. Her unconscious recognition of the values is indicative of formal-operational thought, but the more conscious recognition and attribution of such values reflects more cognitive effort, and thus may be a more reliable indicator of third-order knowing (Lahey et al. 2011).

Using the constructive-developmental lens as an interpretive tool, we can infer that she is not making a choice for or against religious values, since they remain largely invisible to her. Similarly, we may infer for Diane that affiliation or disaffiliation remains largely at the level of personal self-interest, and does not reflect an understanding of the community's mission or values. Were we to use the constructive-developmental lens as a research design tool, we would have been prepared to ask Diane follow up questions about the values embedded in the religious practices. If she can identify them, then we can ask her degree of agreement with them and potentially put those in conversation with the named value of freedom. If she is unable to name them or she presumes they are arbitrary, then we also have more information about how she makes meaning of religious belief and belonging. Either line of questioning and response would offer valuable findings. We would discover if she is disaffiliating in reaction to her parents or to the Church. Whether as an interpretative lens or research design, the constructive-developmental perspective does not ignore Diane and her point of view. Rather, it gives researchers a richer sense of the nature of her disaffiliation, which can be helpful for creating an appropriate response to Diane.

\subsection{Authority and the Possibility of Choice}

Our second example, Edward, shows us someone who clearly has moved beyond the limits of concrete-operations to formal-operations, demonstrated by his ability to recognize values and claim allegiance or affiliation. As such, religious belief and belonging may have a different meaning for Edward than it does for Diane. However, good meaning-making and agency also call us to examine the individual's understanding of that about which they are making meaning and decisions. Is the young person's perception in line with the wider reality or not? Agency is not simply a case of being able to choose or not; agency is heightened when a person is able to choose well. This is tricky, because we may assume that an individual is the best judge of their own experience. Yet, judgement is not made in a vacuum but within a wider world of expectations, and is dependent on reading that wider world well (MacIntyre 1984; Taylor 1989; O'Keefe 2018).

In Edward, we see agency around his choice of allegiance to one community over another, but we also see that his perception of these communities, and their conflict, remains largely unexamined by him—and by the interviewer. Edward says:

I always have been very smart and I was always studious. But as I started to enjoy math and science more I just realized the discrepancy between science and religion. I guess that was another shaking point. Obviously the two can coexist fairly easily, people do it all the time, but for me I was one of those more toward the science end of things. Catholicism, especially, did seem to clash fairly well .... That pushed me away from the Church a bit more because of the belief in science that really didn't stack up with religion as far as agreeing with each other. (McCarty and Vitek 2018, p. 24)

The interview transcript indicates that Edward can think in terms of allegiances and that different communities have different ways of seeing things. A "face value" reading of the interview assumes that Edward's perception of science and Catholicism is accurate and his decision to disaffiliate well 
founded. What remains unexamined in the interview is determining with more clarity on what his decision is based.

While he claims that science and religion do not "stack up", in no instance does he indicate how that is the case. What is apparent is that he sees a duality between science and "Catholicism, especially", but that duality remains assumed and largely unexamined. By his own description, Edward says that "the two can coexist fairly easily" because he sees it in the example of people who "do it all the time", but seems unaware as to how they do it. In this example, a constructive-developmental lens would have been helpful in the interview design. Recognizing that Edward is able to identify that communities have differing visions and values (in this case, science and Catholicism), the interviewer could have asked him to offer a basis for that claim of opposition. Edward's responses may have revealed an informed understanding of the differing values or approaches found in the two communities. Or, he may have offered an uneven discussion: values in one community (perhaps, science's value in empirical fact), and practices on the other (perhaps a literal reading of biblical texts). Either way, the interview would have revealed more richly the basis upon which Edward was making his decisions, which would have been useful.

This in particular is an interesting example. Officially, the Catholic Church does not support opposition to science, and in many instances supports and encourages scientific research and discovery in hospitals, universities, and even the Vatican Observatory. However, in the United States, where there is a strong public presumption of science and Christianity being at odds, it may be that Edward assumes there are differences requiring a judgement in favor of one over the other, based on this public presumption. Or, he may have had a particular experience of Catholic leadership endorsing such a divide. Only further inquiry would unpack the degree to which Edward understands the values embedded in the communities.

This example also points to the importance of having researchers who are sufficiently and widely familiar with the religious communities under examination. A theologically and ecclesially informed interpreter would help the research team better understand an interviewee's perception within the wider community's experience. When the interviewer's perception widely differs, in one instance it may be a case of misinformation, and in another a prophetic witness to a minority perspective. Either way, when it comes to understanding the place of religious belief and belonging in the lives of emerging adults, all these possibilities make research more valuable.

In this section, we have offered two brief examples, working from very limited interview statements. Were we to test this interpretive lens more thoroughly, we would need access to the fuller interviews for the purpose of greater validity. However, even in these brief examples we demonstrate that, by analyzing the material through a constructive-developmental lens, we can better see how the young person is making meaning of religious belief and belonging.

\section{Conclusions}

In this article, we have not conducted any empirical research nor any deep analysis of other research. Rather, we are suggesting that qualitative research on disaffiliation among emerging adults might be better designed and interpreted through the use of a constructive-developmental lens, based on the work of Robert Kegan. This lens would allow for a more nuanced design and reading of religious belief and belonging beyond the "face value" of interviewee's narratives to discover how religious belief and belonging contribute to their meaning-making ability. A better understanding of the cognitive complexity of the research subjects tells us more about the level of agency exhibited in their affiliation or disaffiliation. Furthermore, reading research interviews of emerging adults through a constructive-developmental lens can lead to practical responses for religious ministers and leaders as they work with these populations.

Author Contributions: Conceptualization, T.A.O.; literature review, E.J.; writing-original draft preparation, T.A.O. and E.J.; writing-review and editing, T.A.O. and E.J.; visualization, T.A.O. All authors have read and agreed to the published version of the manuscript. 
Funding: This research received no external funding.

Conflicts of Interest: The authors declare no conflict of interest.

\section{References}

Arnett, Jeffrey Jensen. 2004. Emerging Adulthood: The Winding Road from the Late Teens through the Twenties. New York: Oxford University Press.

Beaudoin, Tom. 2013. Theological Roundtable on Deconversion and Disaffiliation in Contemporary US Roman Catholicism. Horizons 40: 255-62. [CrossRef]

Beaudoin, Tom, and J. Patrick Hornbeck II. 2013. Deconversion and Ordinary Theology: A Catholic Study. In Exploring Ordinary Theology: Everyday Christian Believing and the Church. Edited by Jeff Astley and Leslie J. Francis. Burlington: Ashgate.

Bergler, Thomas. 2005. Book Review Soul Searching: The Religious and Spiritual Lives of American Teenagers. Christian Education Journal 2: 451-55.

Bronfenbrenner, Uri. 1979. The Ecology of Human Development: Experiments by Nature and Design. Cambridge: Harvard University Press.

Bronfenbrenner, Uri. 2005. Making Human Beings Human: Bioecological Perspectives on Human Development. Thousand Oaks: Sage Publications.

Byron, William J., and Charles Zech. 2012. Why They Left. America Magazine, April 30. Available online: http://americamagazine.org/issue/5138/article/why-they-left (accessed on 21 August 2020).

Chan, Melissa, Kim M. Tsai, and Andrew J. Fuligni. 2015. Changes in Religiosity across the Transition to Young Adulthood. Journal of Youth and Adolescence 44: 1555-66. [CrossRef] [PubMed]

Dalessandro, Cristen. 2016. "I don't advertise the fact that I'm a Catholic": College students, religion, and ambivalence. Sociological Spectrum 36: 1-12. [CrossRef]

Funk, Cary, and Greg Smith. 2012. "Nones" on the Rise: One-in-Five Adults Have No Religious Affiliation. Washington: Pew Research Center. Available online: http://www.pewforum.org/2012/10/09/nones-on-the-rise/ (accessed on 21 August 2020).

Kegan, Robert. 1982. The Evolving Self: Problem and Process in Human Development. Cambridge: Harvard University Press.

Kegan, Robert. 1994. In Over Our Heads: The Mental Demands of Modern Life. Cambridge: Harvard University Press.

Kosmin, Barry A., and Ariela Keysar. 2013. Religious, Spiritual, and Secular: The Emergence of Three Distinct Worldviews among American College Students. A Report Based on the ARIS 2013 National College Student Survey. Hartford: Trinity College.

Lahey, Lisa, Emily Souvaine, Robert Kegan, Robert Goodman, and Sally Felix. 2011. A Guide to the Subject-Object Interview: Its Administration and Interpretation. Cambridge: Minds at Work.

MacIntyre, Alasdair. 1984. After Virtue: A Study in Moral Theory. Notre Dame: University of Notre Dame Press.

McCarty, Robert, and John Vitek. 2018. Going, Going, Gone: The Dynamics of Disaffiliation in Young Catholic. Winona: St. Mary's Press.

O'Keefe, Theresa A. 2018. Navigating toward Adulthood: A Theology of Ministry with Adolescents. New York: Paulist Press.

Overstreet, Dawn V. 2010. Spiritual vs. Religious: Perspectives from Today's Undergraduate Catholics. Catholic Education: Journal of Inquiry and Practice 14: 238-63. [CrossRef]

Packard, Josh, and Ashleigh Hope. 2015. Church Refugees: Sociologists Reveal Why People Are DONE with Church but not Their Faith. Loveland: Group Publishing.

Smith, Christian, and Melinda Lundquist Denton. 2005. Soul Searching: The Religious and Spiritual Lives of American Teenagers. New York: Oxford University Press.

Smith, Christian, and Patricia Snell. 2009. Souls in Transition: The Religious and Spiritual Lives of Emerging Adults. New York: Oxford University Press.

Smith, Christian, Kyle Longest, Jonathan Hill, and Kari Christoffersen. 2013. Young Catholic America: Emerging Adults In, Out of, and Gone from the Church. New York: Oxford University Press.

Streib, Heinz, Ralph W. Hood Jr., Keller Barbara, F. Silver Christopher, Csoeff Rosina-Martha, and T. Richardson James. 2009. Deconversion: Qualitative and Quantitative Results from Cross-Cultural Research in Germany and the United States of America. Göttingen: Vandenhoeck and Ruprecht. 
Taylor, Charles. 1989. Sources of the Self: The Making of the Modern Identity. Cambridge: Harvard University Press. Thurston, Angie, and Casper ter Kuile. 2012. How We Gather. Cambridge: Harvard Divinity School. Available online: https://www.howwegather.org/reports (accessed on 21 August 2020).

Publisher's Note: MDPI stays neutral with regard to jurisdictional claims in published maps and institutional affiliations.

(C) 2020 by the authors. Licensee MDPI, Basel, Switzerland. This article is an open access article distributed under the terms and conditions of the Creative Commons Attribution (CC BY) license (http://creativecommons.org/licenses/by/4.0/). 